\title{
PENGARUH RASIO PELARUT TERT-BUTANOL TERHADAP MINYAK DAN SUHU REAKSI GLISEROLISIS PADA PEMBUATAN MONO DAN DIASILGLISEROL (MDAG) MENGGUNAKAN KATALIS ABU CANGKANG TELUR AYAM
}

\author{
Retno Dian Lestari Purba, Margareth Nainggolan, M. Yusuf Ritonga \\ Departemen Teknik Kimia, FakultasTeknik,Universitas Sumatera Utara, \\ Jl. Almamater Kampus USU Medan 20155, Indonesia \\ Email : retnodianpurba@gmail.com
}

\begin{abstract}
Abstrak
Mono dan diasilgliserol (MDAG) merupakan salah satu agen pengemulsi sintesis yang paling banyak digunakan dalam industri makanan. Agen pengemulsi merupakan salah satu produk oleokimia yang bernilai ekonomis tinggi. Penelitian ini bertujuan untuk menghasilkan MDAG melalui proses gliserolisis refined bleached deodorize palm oil dan gliserol dengan pemanfaatan limbah cangkang telur ayam sebagai katalis ( $4 \%$ dari berat minyak) selama 2 jam, dimana variabel uji yaitu rasio tertbutanol terhadap minyak $(1,2$, dan $3 \mathrm{v} / \mathrm{w})$ dan suhu reaksi $\left(60,70\right.$, dan $\left.80^{\circ} \mathrm{C}\right)$. Limbah cangkang telur ayam dikalsinasi pada suhu $900{ }^{\circ} \mathrm{C}$ selama 2 jam sehingga akan dihasilkan katalis $\mathrm{CaO}$ aktif. Selanjutnya dilakukan proses gliserolisis untuk menghasilkan MDAG. MDAG yang dihasilkan dipisahkan dari gliserol pada corong pemisah. Selanjutnya lapisan atas yang terbentuk pada corong pemisah diuapkan untuk memisahkan MDAG dengan tert-butanol. Kadar MDAG dianalisis menggunakan Kromatografi Gas. Hasil terbaik diperoleh pada temperatur $70{ }^{\circ} \mathrm{C}$, rasio co-solvent tert-butanol terhadap minyak 3:1 (v/w), waktu reaksi 2 jam, dan jumlah katalis $4 \%$ dari minyak dengan kadar MDAG sebesar 68,62\%. MDAG yang diperoleh merupakan emulsifier w/o dengan Hydrophilic Lipophilic Balance yaitu 5,19. Hasil yang diperoleh dari penelitian ini menunjukkan bahwa limbah cangkang telur ayam cocok digunakan sebagai sumber katalis untuk memproduksi mono dan diasilgliserol.
\end{abstract}

Kata kunci: cangkang telur, co-solvent, gliserolisis, mono dan diasilgliserol

\begin{abstract}
Mono and diacylglycerol (MDAG) is one of the synthetic emulsifier agent widely used in food industry. Emulsifier agent is one of the economically high value oleochemical product. The purpose of this research is to produce MDAG through glycerolysis process of refined bleached deodorize palm oil (RBDPO) and glycerol by using egg shell waste as catalyst (4\% of oil weight) for 2 hours, whereas the variables ratio of tert-butanol to oil $(1,2,3 \mathrm{v} / \mathrm{w})$ and reaction temperatur (60, 70 and 80 $\left.{ }^{\circ} \mathrm{C}\right)$. Egg shell waste was calcined at $900{ }^{\circ} \mathrm{C}$ for 2 hours to form active $\mathrm{CaO}$ catalyst. Then glycerolysis process to produce mono and diacylglyserol. Mono and diacylglycerol that formed was separated by using separator fannel. The upper layer was vaporated to separate MDAG from tertbutanol. The content of MDAG was analyzed using Gas Chromatography. The best result was at 70 ${ }^{\circ} \mathrm{C}$ temperature, ratio co-solvent to oil 3:1 (v/w), 2 hours of reaction time and $4 \%$ of catalyst amount from oil and oil molar ratio to glycerol 1:6 with MDAG content of 68,62\%. MDAG formed are w/o emulsifier with $5.19 \mathrm{HLB}$. The result of this research shows that egg shell waste is suitable to be used as source of cheap catalyst to produce mono and diacylglycerol.
\end{abstract}

Keywords: co-solvent, egg shell, glycerolysis, mono and diacylglyserol

\section{Pendahuluan}

Mono dan diasilgliserol merupakan emulsifier (agen pengemulsi) sintesis yang paling banyak digunakan dalam industri makanan dengan status GRAS (generally recognized as safe) sehingga aman untuk dikonsumsi [10]. Mono dan diasilgliserol serta turunannya diproduksi sebagai pengemulsi makanan sekitar $70 \%$ di seluruh dunia [12]. Selebihnya digunakan pada industri kosmetik, farmasi, dan lain-lain [23].
Gliserolisis katalis basa merupakan suatu metode yang biasa digunakan untuk menghasilkan monogliserida. Pada reaksi gliserolisis asam lemak atau minyak dan gliserol membentuk sebuah sistem dua fasa [16]. Pada temperatur yang rendah, gliserol dan minyak atau lemak tidak dapat saling larut (bercampur) [3].

Untuk membentuk reaksi dengan sistem satu fasa, ditambahkan suatu pelarut yang dapat 
meningkatkan kelarutan minyak dan gliserol, sebab reaksi homogen secara keseluruhan dapat dicapai dengan menggunakan co-solvent serta keterbatasan transfer massa dapat diatasi [20]. Alkohol alifatis merupakan pilihan baik karena mampu melarutkan gliserol dan minyak (TAG) membentuk larutan pseudo-homogeneous [3].

Umumnya, laju reaksi lebih cepat dengan penggunaan katalis basa dibandingkan dengan katalis asam [11]. Berdasarkan fasanya, katalis heterogen lebih mudah dipisahkan dibandingkan katalis homogen. Sehingga dalam penelitian ini digunakan katalis basa heterogen, yaitu $\mathrm{CaO}$.

$\mathrm{CaO}$ diperoleh dari kalsinasi cangkang telur ayam. Sehingga pemanfaatan limbah dari cangkang telur diharapkan dapat menambah nilai ekonomis dari cangkang telur tersebut dimana selama ini cangkang telur yang telah dikalsinasi pada suhu tinggi telah banyak dimanfaatkan sebagai katalis reaksi transesterifikasi [8].

Berdasarkan uraian di atas maka telah dilakukan suatu penelitian mengenai gliserolisis refined bleached deodorize palm oil (RBDPO) dan gliserol dengan memanfaatkan abu cangkang telur ayam sebagai katalis untuk menghasilkan mono dan diasilgliserol (MDAG) pada suhu reaksi rendah.

\section{Teori}

Refined Bleached Deodorize Palm Oil (RBDPO) merupakan minyak sawit mentah yang telah dimurnikan melalui tahapan degumming, netralisasi, dekolorisasi dan deodorisasi. Minyak sawit mentah (CPO) kaya akan oleat dan palmitat yang terikat sebagai trigliserida dan sekitar $50 \%$ asam lemak jenuh [15, 29]. RBDPO memiliki kandungan asam lemak jenuh yang lebih tinggi dibandingkan CPO dan kandungan asam lemak tidak jenuh yang lebih rendah dibandingkan CPO [26].

Gliserol (1,2,3-propanatriol) atau dikenal dengan istilah gliserin merupakan alkohol sederhana dengan banyak manfaat seperti pada pembuatan kosmetik, cat, otomotif, makanan, pharmaceutical, pulp dan kertas, industri kertas atau sebagai umpan untuk produksi bahan-bahan kimia [28]. Menurut The Soap and Detergent Association [24], istilah gliserin digunakan untuk produk komersil yang dimurnikan, mengandung $95 \%$ atau lebih dari gliserol. Gliserin merupakan cairan tidak berwarna, tidak berbau dan berasa manis, bersifat higroskopis dan bertekstur kental. Gliserin memiliki titik didih $290{ }^{\circ} \mathrm{C}$ dan titik beku $20{ }^{\circ} \mathrm{C}$. Gliserin larut dalam air, alkohol, dan eter namun tidak larut dalam minyak [5].

Pemilihan co-solvent yang sesuai yaitu berdasarkan nilai log $\mathrm{P}$ dari co-solvent tersebut. Co-solvent dengan nilai $\log \mathrm{P}$ yang kecil diindikasikan memiliki karakteristik hidrofil dan hidrofobik [18]. Berdasarkan percobaan yang telah dilakukan oleh Zhong, dkk., [21], pembentukan DAG yang diamati pada tertbutanol dan tert-pentanol memperoleh pembentukan DAG tertinggi dalam sistem iradiasi ultrasonic, diikuti oleh magnetic stirring dan sistem pengadukan mekanis dengan nilai log $\mathrm{P}$ untuk tert-butanol ialah 0,35 . Sehingga tertbutanol merupakan pelarut yang sesuai untuk meningkatkan transfer massa dan mempercepat laju reaksi karena dapat meningkatkan kelarutan minyak dan gliserol secara pesat pada temperatur rendah .

Emulsi merupakan sistem heterogen yang terdiri atas dua fase cairan yang tidak tercampur tetapi cairan yang satu terdispersi dengan baik dalam cairan yang lain dalam bentuk butiran (droplet/globula) [14]. Sistem emulsi diklasifikasikan berdasarkan distribusi minyak dan fasa air. Sebuah sistem yang terdiri dari tetesan minyak terdispersi dalam fasa air disebut minyak dalam air atau emulsi o/w (misalnya, mayones, susu, krim, sup, dan saus) dan sebuah sistem yang terdiri dari tetesan air terdispersi dalam fase minyak disebut air-dalam-minyak atau emulsi w/o (misalnya, margarin dan mentega) [19].

Metode pengklasifikasian pengemulsi sesuai sifat fisika-kimianya melalui konsep Hydrophilic Lipophilic Balance (HLB) menurut Hans, dkk., [12] paling banyak digunakan. Emulsifier yang semakin bersifat hidrofilik memiliki nilai HLB tinggi. Hal ini juga dikemukakan Ahmad [1] bahwa nilai HLB yang semakin rendah maka emulsifier tersebut semakin bersifat lipofilik. Pengaplikasian emulsifier dibedakan berdasarkan nilai HLBnya sebagaimana ditunjukkan pada tabel 1 .

Tabel 1. Rentang HLB terhadap Aplikasi Emulsifier [12]

\begin{tabular}{|l|l|}
\hline Rentang HLB & Aplikasi \\
\hline $0-3$ & Antifoaming \\
$4-6$ & Emulsifier w/o \\
$7-9$ & Wetting agent \\
$8-18$ & Emulsifier o/w \\
$13-15$ & Detergen \\
$10-18$ & Stabilizer \\
\hline
\end{tabular}

Berdasarkan nilai HLBnya, Hans, dkk., [12] mengklasifikasikan monogliserida sebagai emulsifier lipofilik. Monogliserida dapat larut dengan sempurna dalam lemak atau minyak dan terdispersi dalam air pada kondisi tertentu [9]. 
Gliserolisis merupakan salah satu reaksi untuk menghasilkan mono dan diasilgliserol (MDAG). Gliserolisis merupakan proses dimana ester bereaksi dengan gliserol. Sintesis mono dan diasilgliserol melalui proses esterifikasi langsung dan interesterifikasi (gliserolisis) dapat dilihat pada gambar 1 berikut.

$$
\begin{aligned}
& \text { (i) Esterifikasi Langsung : }
\end{aligned}
$$

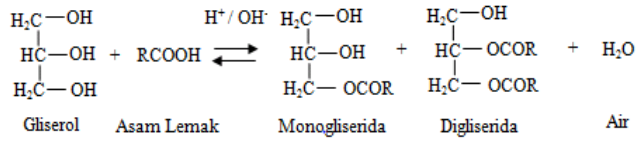

$$
\begin{aligned}
& \text { (ii) Interesterifikasi (Gliserolisis). }
\end{aligned}
$$

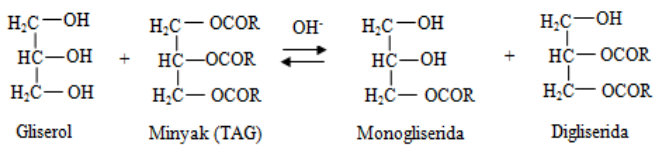

Gambar 1. Sintesis Mono dan Diasilgliserol melalui Esterifikasi Langsung dan Interesterifikasi (Gliserolisis) [10]

Reaksi gliserolisis dalam pembuatan mono dan diasilgliserol dipengaruhi oleh beberapa variabel penting, diantaranya, temperatur reaksi, jenis dan jumlah katalis, rasio molar gliserol minyak, intensitas pencampuran dan waktu reaksi [17]. Pada suhu kamar, kelarutan gliserol dalam trigliserida kurang dari 5\% berat, tetapi meningkat menjadi sekitar $45-55 \%$ berat pada suhu setinggi $250{ }^{\circ} \mathrm{C}$ [13]. Namun pada suhu reaksi gliserolisis yang tinggi menyebabkan produk yang dihasilkan berwarna gelap dan terbentuk bau yang tidak diinginkan [4].

\section{Metodologi Penelitian}

Dalam penelitian ini, digunakan refined bleached deodorized palm oil (RBDPO), gliserol, limbah cangkang telur ayam, tert-butanol, heksana sebagai bahan utama dan asam klorida, etanol, alkohol, $\mathrm{NaOH}$ sebagai bahan untuk analisa.

Alat yang digunakan dalam penelitian ini adalah beaker glass, statif dan klem holder, labu leher tiga, water bath, stirer, refluks kondensor, termometer, hot plate, neraca analisis, furnace, oven, gelas ukur, erlenmeyer, kertas saring, ball mill, dan ayakan 140 mesh.

Tahap awal adalah preparasi abu cangkang telur ayam dengan cara membersihkan cangkang telur ayam dengan air keran hingga bersih dan dikeringkan. Cangkang telur ayam, yang telah kering dihancurkan menjadi lebih kecil dengan lumping dan alu serta digiling menjadi serbuk dengan ball mill. Serbuk cangkang telur ayam diayak dengan ayakan 140 mesh. Hasil ayakan yang lolos dipanaskan dalam furnace selama 2 jam dengan suhu $900{ }^{\circ} \mathrm{C}$ [25]
Tahap selanjutnya adalah proses gliserolisis dengan mengadopsi prosedur yang dilakukan oleh Yanuar dan Sri [27] dan Farida [9] yaitu RBDPO sebanyak 10 gr dipanaskan sampai suhu $105{ }^{\circ} \mathrm{C}$ untuk mengurangi kadar air. RBDPO dan pelarut tert-butanol dengan variasi rasio volume tert-butanol dengan massa $\operatorname{RBDPO}(1,2,3)$ dimasukkan ke dalam labu leher tiga. Campuran RBDPO dan tert-butanol dipanaskan hingga mencapai temperatur reaksi. Gliserol sebanyak 6,474 gr dan katalis sebanyak $4 \%$ dari RBDPO dipanaskan di tempat terpisah hingga mencapai temperatur reaksi. Setelah suhu reaksi tercapai maka gliserol dan katalis abu kulit telur, yaitu 0,6046 gram dimasukkan ke dalam campuran yang terdapat pada labu leher tiga. Dilakukan pengadukan dengan kecepatan 400 rpm dan dipertahankan pada temperatur reaksi dengan variasi 60, 70 dan $80{ }^{\circ} \mathrm{C}$. Pemanasan dan pengadukan dihentikan setelah waktu reaksi tercapai, yaitu 120 menit Katalis abu cangkang telur ayam dipisahkan dengan menggunakan penyaringan. Filtrat yang diperoleh dicuci dengan heksana untuk memisahkan gliserol dan diuapkan. Produk yang diperoleh ditimbang beratnya lalu dilakukan analisa.

\section{Hasil dan Pembahasan \\ Hasil Analisis Komposisi Asam Lemak RBDPO}

Penelitian ini dilakukan dengan menggunakan bahan baku berupa refined bleached deodorized palm oil (RBDPO) yang mengandung asam oleat tertinggi yaitu 44,9306 \%. Komposisi asam lemak dari RBDPO disajikan pada tabel 2.

Tabel 2. Komposisi Asam Lemak dari Refined Bleached Deodorized Palm Oil (RBDPO)

\begin{tabular}{|c|l|r|}
\hline No. & Komponen Penyusun & \multicolumn{1}{|c|}{$\begin{array}{c}\text { Komposisi } \\
\mathbf{\%}(\mathbf{b} / \mathbf{b})\end{array}$} \\
\hline 1 & Asam Laurat (C12:0) & 0,3020 \\
2 & Asam Miristat (C14:0) & 0,9911 \\
3 & Asam Palmitat (C16:0) & 36,8848 \\
4 & Asam Palmitoleiat (C16:1) & 0,1878 \\
5 & Asam Stearat (C18:0) & 3,9939 \\
6 & Asam Oleat (C18:1) & 44,9306 \\
7 & Asam Linoleat (C18:2) & 11,9121 \\
8 & Asam Linolenat (C18:3) & 0,2522 \\
9 & Asam Arakidat (C20:0) & 0,3760 \\
10 & Asam Eikosenoat (C20:1) & 0,1694 \\
\hline
\end{tabular}

Berdasarkan data komposisi asam lemak dari RBDPO maka dapat ditentukan bahwa berat molekul RBDPO (dalam bentuk trigliserida) adalah $852,6981 \mathrm{gr} / \mathrm{mol}$ sedangkan berat molekul asam lemak bebas RBDPO adalah 271,566 $\mathrm{gr} / \mathrm{mol}$. 


\section{Hasil Analisis Kadar Asam Lemak bebas RBDPO}

Keberadaan asam lemak bebas (ALB) dalam minyak akan mempengaruhi mutu daripada minyak tersebut. Asam lemak bebas lebih mudah teroksidasi sehingga akan menyebabkan bau tengik pada minyak [9]. Berdasarkan hasil analisis diperoleh kadar asam lemak bebas RBDPO sebesar 0,03\%. Berdasarkan Standar Nasional Indonesia (SNI 01-0018-2006) mengenai RBDPO, kadar asam lemak bebas dalam minyak maksimal adalah sebesar 0,15\% [26]. Karena kadar asam lemak bebas RBDPO rendah (ALB<0,15\%), maka RBDPO tidak perlu dilakukan proses esterifikasi terlebih dahulu.

\section{Hasil Analisis Kadar Air RBDPO}

Tingginya kadar air akan menyebabkan terjadinya reaksi hidrolisis minyak/lemak dengan katalis menghasilkan asam lemak bebas [1]. Berdasarkan Standar Nasional Indonesia (SNI 01-0018-2006) tentang RBDPO disebutkan bahwa persyaratan kadar air yang terkandung dalam RBDPO adalah sebesar 0,1\% [7]. Kadar air bahan baku RBDPO yang digunakan pada penelitian ini adalah $0,16 \%$. Oleh karena itu, sebelum direaksikan RBDPO dipanaskan terlebih dahulu sampai suhu $105{ }^{\circ} \mathrm{C}$ untuk mengurangi kadar airnya.

\section{Hasil Preparasi Abu Cangkang Telur Ayam}

Kalsium oksida $(\mathrm{CaO})$ merupakan alkali tanah oksida yang memiliki aktivitas katalitik cukup tinggi dan terbentuk dari kalsinasi kalsium karbonat $\left(\mathrm{CaCO}_{3}\right)$ pada suhu tinggi [22]. Berdasarkan hasil penelitian yang dilakukan oleh Ali, dkk [2] diperoleh kondisi optimum proses kalsinasi $\mathrm{CaO}$ dari limbah kulit telur ayam pada suhu $900{ }^{\circ} \mathrm{C}$ dan waktu 2 jam. Kadar kalsium oksida $(\mathrm{CaO})$ dan kadar air yang terkandung di dalam abu cangkang telur ayam disajikan dalam tabel 3 berikut.

Tabel 3. Kadar Kalsium Oksida (CaO) dan Kadar Air di dalam Abu Cangkang Telur Ayam

\begin{tabular}{|c|c|c|c|}
\hline Parameter & Satuan & $\begin{array}{c}\text { Hasil } \\
\text { Uji }\end{array}$ & Metode Uji \\
\hline $\mathrm{CaO}$ & $\%$ & 66,16 & $\begin{array}{c}\text { Ik.01.P.05 } \\
\text { (AAS) } \\
\text { Oven }\end{array}$ \\
\hline
\end{tabular}

Pengaruh Rasio Pelarut Tert-Butanol dengan Minyak terhadap Kadar Mono dan Diasilgliserol (MDAG)

Hubungan antara rasio pelarut tert-butanol dengan minyak terhadap kadar MDAG dengan berbagai variasi temperatur reaksi gliserolisis pada kondisi waktu reaksi 120 menit, katalis $4 \%$ dan rasio mol gliserol dengan minyak 6:1 dapat dilihat pada gambar 2 .

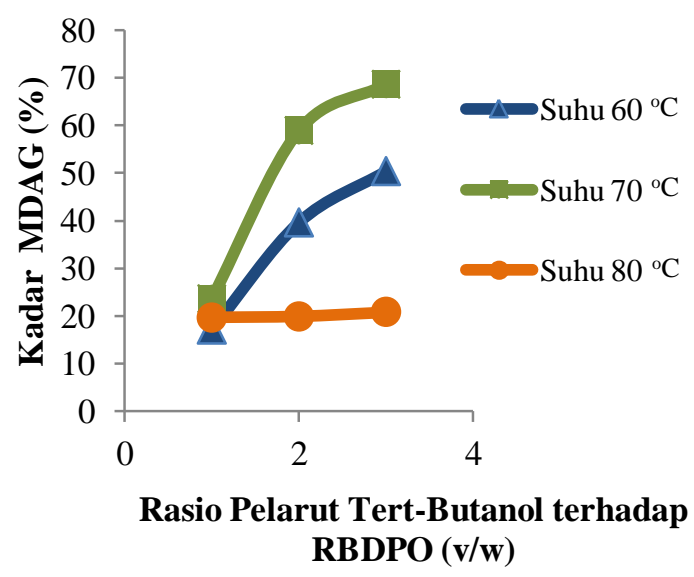

Gambar 2. Pengaruh Rasio Pelarut Tert-Butanol dengan Minyak terhadap Kadar MDAG

Gambar 2 di atas menunjukkan bahwa semakin besar penambahan jumlah pelarut tertbutanol yang digunakan maka kadar dari mono dan diasilgliserol yang diperoleh semakin meningkat pada suhu reaksi konstan yaitu $60{ }^{\circ} \mathrm{C}$, $70{ }^{\circ} \mathrm{C}$ dan $80{ }^{\circ} \mathrm{C}$. Pada suhu $70{ }^{\circ} \mathrm{C}$ dengan rasio tert-butanol dengan minyak adalah $3 / 1$ (v/w) menghasilkan kadar MDAG yang lebih tinggi. Hal ini menunjukkan bahwa dengan penambahan tert-butanol sebagai co-solvent maka minyak (TAG) dan gliserol lebih banyak melarut sehingga TAG yang bereaksi lebih besar.

Minyak (TAG) tidak dapat larut dalam gliserol pada temperatur rendah (temperatur reaksi $<200{ }^{\circ} \mathrm{C}$ ) [4]. Sehingga dengan penambahan co-solvent mampu meningkatkan kelarutan minyak dan gliserol pada suhu rendah. Tert-butanol merupakan co-solvent yang sesuai untuk meningkatkan kelarutan minyak dan gliserol. Semakin banyak jumlah co-solvent yang ditambahkan, kelarutan minyak akan meningkat sehingga reaksi akan berjalan semakin baik [20]. Namun dalam skala industri, penggunaan pelarut dalam jumlah banyak dinilai kurang ekonomis [21].

Berdasarkan hasil percobaan yang telah dilakukan, kondisi terbaik yang didapatkan adalah pada perbandingan tert-butanol dengan minyak adalah $3: 1(\mathrm{v} / \mathrm{w})$, suhu $70{ }^{\circ} \mathrm{C}$, waktu reaksi 120 menit, katalis $4 \%$ dari massa RBDPO dan rasio mol gliserol dan minyak 6:1 yang memberikan kadar MDAG sebesar 68,6217\%.

Pengaruh Rasio Pelarut Tert-Butanol dengan Minyak terhadap Kadar Mono dan Diasilgliserol (MDAG)

Hubungan antara suhu reaksi gliserolisis terhadap kadar MDAG dengan berbagai variasi rasio pelarut tert-butanol dengan minyak pada 
kondisi waktu reaksi 120 menit, katalis $4 \%$ dan rasio mol gliserol dengan minyak 6:1 dapat dilihat pada gambar 3 .

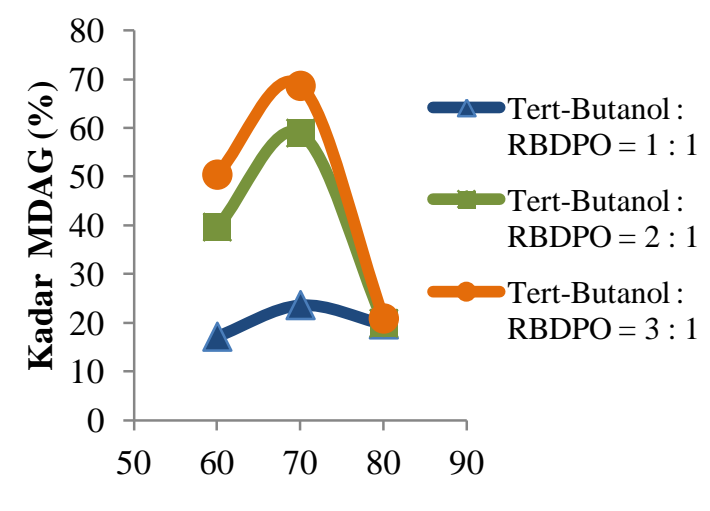

Suhu Reaksi ( $\left.{ }^{\circ} \mathrm{C}\right)$

Gambar 3. Pengaruh Suhu Reaksi terhadap Kadar MDAG

Gambar 3 di atas menunjukkan bahwa semakin tinggi suhu reaksi maka kadar MDAG yang dihasilkan semakin meningkat pula. Namun mengalami penurunan pada saat suhu reaksi mencapai titik didih co-solvent yang digunakan.

Suhu yang tinggi akan menurunkan viskositas larutan, sehingga nilai diffusivitas molekul A ke dalam molekul B menjadi lebih besar, sehingga tumbukan antar molekul lebih banyak terjadi dan produk yang dihasilkan menjadi lebih besar [4]. Selain itu, meningkatnya temperatur juga meningkatkan interaksi antara reaktan dan katalis [3].

Berdasarkan hasil percobaan, kadar MDAG meningkat seiring meningkatnya suhu reaksi, namun mengalami penurunan pada suhu mendekati titik didih tert-butanol yaitu pada suhu reaksi $80{ }^{\circ} \mathrm{C}$. Adapun titik didih tert-butanol yaitu $82,14{ }^{\circ} \mathrm{C}$ [6]. Perubahan fasa tert-butanol pada suhu reaksi $80{ }^{\circ} \mathrm{C}$, menyebabkan kelarutan gliserol dalam minyak (TAG) mengalami penurunan sehingga tumbukan antar molekul reaktan akan berkurang. Hal ini juga menyebabkan viskositas larutan semakin tinggi sehingga transfer massa dan laju reaksi semakin menurun.

Berdasarkan hasil penelitian yang dilakukan oleh Yanuar dan Sri [27] dengan menggunakan co-solvent, reaksi gliserolisis pada suhu di bawah titik didih co-solvent yang digunakan akan mengalami peningkatan konversi seiring kenaikan suhu namun mengalami penurunan konversi setelah mencapai titik didih co-solvent yang digunakan.

Berdasarkan hasil percobaan yang telah dilakukan, kondisi terbaik yang didapatkan adalah pada suhu reaksi $70{ }^{\circ} \mathrm{C}$, perbandingan tert-butanol dengan minyak adalah 3:1 (v/b), waktu reaksi 120 menit, katalis $4 \%$ dari massa RBDPO dan rasio mol gliserol dan minyak 6:1 yang memberikan kadar MDAG 68,6217\%.

\section{Analisa Asam Lemak Bebas Mono dan Diasilgliserol (MDAG)}

Adapun kadar asam lemak bebas yang terkandung di dalam produk diharapkan sekecil mungkin. Kadar asam lemak bebas yang tinggi dalam produk MDAG kurang menguntungkan karena akan menyebabkan rendahnya daya emulsifikasi produk [9]. Semakin tinggi kadar asam lemak bebas berarti kandungan MDAG dalam produk berkurang sehingga daya emulsifikasi produk rendah. Selain itu, asam lemak bebas tinggi memungkinkan tingkat oksidasi semakin tinggi pula sehingga memungkinkan timbulnya bau yang tidak enak off odor yang dapat mengurangi penerimaan produk di tingkat konsumen

Berdasarkan hasil analisis asam lemak bebas produk diperoleh kadar asam lemak bebas mono dan diasilgliserol (MDAG) yang didapatkan yaitu $0,55 \%$. Kadar asam lemak bebas yang diperoleh ini lebih rendah dibandingkan kadar asam lemak bebas komersial yang dilaporkan oleh Ahmad [1] yaitu 1,34\%.

\section{Analisis Hydrophilic Lipophilic Balance (HLB)}

Suatu nilai yang digunakan untuk mengekspresikan keseimbangan hidrofil-lipofil dalam suatu sistem emulsi ialah nilai HLB (Hydrophilic Lipophilic Balance) [12]. Menurut Ahmad [1], semakin rendah nilai HLBnya maka emulsifier tersebut semakin bersifat lipofilik. Mono dan diasilgliserida diklasifikasikan sebagai emulsifier lipofilik atau emulsifier w/o dengan rentang HLB yaitu 4-6 [12]. Berdasarkan hasil analisis hydrophilic lipophilic balance (HLB) mono dan diasilgliserol (MDAG) didapatkan nilai HLBnya yaitu 5,19. Berdasarkan refrensi di atas, dapat disimpulkan bahwa mono dan diasilgliserol (MDAG) yang dihasilkan merupakan emulsifier water in oil (w/o).

\section{Kesimpulan}

Limbah cangkang telur ayam dapat dimanfatkan sebagai katalis heterogen dalam pembuatan mono dan diasilgliserol dengan kandungan $\mathrm{CaO}$ setelah dikalsinasi sebesar $66,16 \%$. Meningkatnya rasio pelarut tert-butanol dengan minyak dan suhu reaksi maka kadar mono dan diasilgliserol juga semakin meningkat. Kondisi terbaik diperoleh pada rasio tert-butanol dengan RBDPO 3:1 (v/w) dan suhu reaksi $70{ }^{\circ} \mathrm{C}$ dengan kadar mono dan diasilgliserol sebesar $68,6217 \%$. Kadar asam lemak bebas dari mono dan diasilgliserol yang dihasilkan sebesar 0,55\% 
dan nilai HLB 5,19 yang merupakan emulsifier water in oil (w/o).

\section{Daftar Pusataka}

[1] Ahmad Zaelani, "Sintesis Mono dan Diasilgliserol dari Refined Bleached Deodorized Palm Oil (RBDPO) dengan Cara Gliserolisis Kimia”, Skripsi, Institut Pertanian Bogor, 2007.

[2] Ali A. Jazie, Pramanik, H. dan Sinha, A. S. K., Egg Shell As Eco-Friendly Catalyst for Transesterification of Rapeseed Oil : Optimization for Biodiesel Production, Special Issue of International Journal of Suistanable Development and Green Economics (IJSDGE), 2(1) 2013 : hal. 27 32

[3] Andri Cahyo Kumoro, "Experimental and Modeling Studies of the Reaction Kinetics of Alkaline-Catalyzed used Frying Oil Glycerolysis using Isopropyl Alcohol as a Reaction Solvent", Research Journal of Applied Sciences, Engineering and Technology, 4(8) 2012 : hal. 869 - 870.

[4] Anisa Harismawati dan Fajar Prasetyo, "Produksi Mono- dan Digliserida dengan Proses Gliserolisis Pseudohomogen dari Minyak Goreng Bekas", Skripsi, Universitas Diponegoro, Semarang, tth.

[5] Badan POM RI (2011), Gliserin. Diakses pada 18 Maret 2014. http://ik.pom.go.id

[6] Badan POM RI (2012), T-Butil Alkohol. Diakses pada 18 Maret 2014. http://ik.pom.go.id.

[7] Badan Standarisasi Nasional (2006), Standar Nasional Indonesia. Diakses pada 27 Agustus 2014. http:// www.bsn.com.

[8] Ekky Riza Enggawati dan Ratna Ediati, "Pemanfaatan Kulit Telur Ayam dan Abu Layang Batubara sebagai Katalis Heterogen untuk Reaksi Transesterifikasi Minyak Nyamplung (Calophyllum Inophyllum Linn)", Jurnal Sains dan Seni POMITS, 2(1) 2013 : hal. 2337 - 3520.

[9] Farida Nuraeni, "Sintesis Mono dan Diasilgliserol (M-DAG) dari Destilat Asam Lemak Minyak Sawit (DALMS) melalui Esterifikasi Enzimatik", Tesis, Sekolah Pascasarjana Institut Pertanian Bogor, 2008.

[10] Gerard L Hasenhuettl dan Richard W. Hartel (Eds), "Synthesis and Commercial Preparation of Food Emulsifiers", dalam Food Emulsifiers and Their Applications, (New York: Springer, 2008).

[11] Guomin Xiao dan Lijing Gao (tth), First Generation Biodiesel. Diakses 3 Februari 2014. http://www.intechopen.com

[12] Hans Moonen, Henny Bas dan Robert J. Whitehurst (Eds), "Mono- and
Diglycerides", dalam Emulsifier in Food Technology, (Oxford: Blackwell Publishing Ltd., 2004).

[13] Hossein Noureddini, D.W. Harkey dan M.R. Gutsman, "A Continuous Process for the Glycerolysis of Soybean Oil”, Papers in Biomaterials, Chemical and Biomolecular Engineering Research and Publications, University of NebraskaLincoln, 2004.

[14] Irma Rita, "Proses Emulsifikasi dan Analisis Biaya Produksi Minuman Emulsi Minyak Sawit Merah", Tesis, Sekolah Pascasarjana Institut Pertanian Bogor, 2011.

[15] Jan Willem van Gelder, Greasy Palms : European Buyers of Indonesian Palm Oil, (London : Friends of the Earth, 2004).

[16] Kimmel, Tobias, "Kinetic Investigation of the Base-Catalyzed Glycerolysis of Fatty Acid Methyl Esters", Technischen Universität Berlin, 2004.

[17] Kombe, Godlisten G., Abraham K. Temu, Hassan M. Rajabu, Godwill D. Mrema dan Keat Teong Lee, "Low Temperature Glycerolysis as a High FFA Pre-Treatment Method for Biodiesel Production", Advances in Chemical Engineering and Science, 3 (2013), hal. 248.

[18] M. L. Damstrup, T. Jensen, F. V. Sparso, A. D. Jensen dan $\mathrm{X}$. $\mathrm{Xu}$, "Solvent Optimization for Efficient Enzymatic Monoacylglycerol Production Based on a Glycerolysis Reaction", JAOCS, 82(8) 2005 : hal. 559-564.

[19] Mc Clements, David Julian, Food Emultions, (New York: CRC Press LCC, 1999).

[20] Muyassaroh, Elvianto Dwi Daryono, dan M. Istnaeny Hudha, "Biodiesel dari Minyak Jarak Pagar dengan Variasi Penambahan Co-Solvent dan Waktu Reaksi”, Jurnal Teknik Kimia, 7(1) 2012 : hal. 8 - 11.

[21] Nanjing Zhong, Lin Li, Xuebing Xu, LingZhi Cheong, Xihong Zhao dan Bing Li, "Production of Diacylglycerols through Low-Temperature Chemichal Glycerolysis, Food Chemistry, Elsevier, 122, 2010 : hal. 228-232.

[22] Samik, Ratna Ediati, dan Didik Prasetyoko, "Review: Pengaruh Kebasaan dan Luas Permukaan Katalis Terhadap Aktivitas Katalis Basa Heterogen untuk Produksi Biodiesel", Prosiding Seminar Nasional Kimia Unesa, 7(1) 2011 : hal. 462 - 468.

[23] Sophie Maadin Noviani dan Yuanita Sekar Hapsari, "Proses Gliserolisis Minyak Kelapa Sawit Menjadi Mono dan Diasil Gliserol dengan Pelarut N-Butanol dan 
Katalis MgO", Skripsi, Jurusan Teknik

Kimia, Fakultas Teknik, Universitas Diponegoro, 2009.

[24] The Soap and Detergent Association, "Glycerine : an Overview", 475 Park Avenue South, New York, 1990.

[25] Viriya-Empikul, N., Krasae, P., Puttasawat, B., Yoosuk, B., Chollacoop, N., Faungnawakij, K., Waste Shells of Mollusk and Egg As Biodiesel Production Catalysts, Bioresource Technology, 101(1), 2009.

[26] Y.B. Che Man, T. Haryati, H.M. Ghazali dan B.A. Asbi, "Composition and Thermal Profile of Crude Palm Oil and Its Products", JAOCS, 76(2) 1999: hal. 237-242

[27] Yanuar Sigit Pramana dan Sri Mulyani, "Proses Gliserolisis CPO Menjadi Mono dan Diacyl Gliserol dengan Pelarut TertButanol dan Katalis MgO", Skripsi, Universitas Diponegoro, 2010.

[28] Zheng Xiang Wang, Jian Zhuge, Huiying Fang dan Bernard A. Prior, "Glycerol Production by Microbial Fermentation: A Review", Biotechnology Advances, 19(1) 2001 : hal. 201 - 202

[29] Zul Alfian, “ Perbandingan Hasil Analisis Beberapa Parameter Mutu pada Crude Palm Olein yang Diperoleh dari Pencampuran CPO dan RBD Palm Olein terhadap Teoretis", Jurnal Sains Kimia, 10 (2) 2006 : hal. $46-50$. 